\title{
Pressurized intraperitoneal aerosol chemotherapy in nonresectable carcinomatosis from colorectal cancer
}

\author{
Nicolae BACALBASA ${ }^{1,2}$, Irina BALESCU ${ }^{3}$, Adnan Al ALOUL ${ }^{4,5}$ \\ ${ }^{1}$ Department of Visceral Surgery, Center of Excellence in Translational Medicine, Fundeni Clinical \\ Institute, Bucharest, Romania \\ 2Department of Obstetrics and Gynecology, "Carol Davila" University of Medicine and Pharmacy, \\ Bucharest, Romania \\ ${ }^{3}$ Department of Surgery, Ponderas Academic Hospital, Bucharest, Romania \\ ${ }^{4}$ Department of Surgery, Ramnicu Sarat County Hospital, Buzau, Romania \\ ${ }^{5}$ Doctoral School, "Titu Maiorescu“ University, Bucharest, Romania
}

\begin{abstract}
Peritoneal carcinomatosis colorectal cancer unfortunately represents a frequently encountered condition during the natural history of this malignancy which has been considered for a long period of time as a terminal event. However, once new surgical and oncological therapies have been reported significant changes have been reported in the management of these cases. Therefore, cytoreductive surgery to no residual disease as a stand-alone procedure or in association with intraperitoneal hyperthermic chemotherapy has been proposed and significant benefits in terms of survival have been reported; unfortunately not all patients with peritoneal carcinomatosis are candidates for this combined approach, especially if extended, nonresectable lesions are present. In such cases pressurized intraperitoneal aerosol chemotherapy (PIPAC) has been proposed with promising results. The aim of the current paper is to review the most important studies conducted on this issue.
\end{abstract}

Keywords: PIPAC, peritoneal carcinomatosis, morbidity, survival

\section{INTRODUCTION}

Colorectal cancer represents one of the most commonly encountered malignancies worldwide and, in the meantime an important cause of cancer related death (1). Although rectal cancer usually leads to the apparition of alarming signs such as constipation, rectal bleeding, abdominal pain and modifications of the aspect of the stool, a significant number of patients ignore these signs and are submitted to colonoscopy only late during the course of the disease (2-4); there- fore, the final diagnosis is established lately during the course of the disease, when local invasion of the surrounding organs or distant metastases are already present. When it comes to the ways of dissemination, the most commonly encountered routes are represented by the peritoneal and hematogenous ones, leading to the apparition of peritoneal nodules and parenchimatous metastases respectively (5-8). While the development of parenchimatous, lesions is considered as the sign of systemic spread of the disease, the apparition of peritoneal lesions is rather considered as the 
sign of local spread of the malignant cells via the peritoneal route, facilitated by the presence of small amounts of free peritoneal liquid $(9,10)$.

\section{THERAPEUTIC STRATEGIES IN PATIENTS WITH PERITONEAL CARCINOMATOSIS FROM COLORECTAL CANCER}

Once the above mentioned theory has been widely approved, patients presenting peritoneal carcinomatosis have been considered lately as cases with locally disseminated disease and were therefore submitted to surgery with curative intent (11). The most efficient such therapeutic strategy is represented by cytoreductive surgery to no residual disease in association with intraperitoneal heated chemotherapy (12-14). The method proved to be an efficient one and the results in terms of survival demonstrated a significant benefit; therefore, it became widely accepted. However, the most important condition in order to maximize the effects in terms of survival is represented by achieving a complete cytoreductive surgery, desiderate which might be difficult to be obtained especially when disseminated and extended peritoneal lesions are present. In order to diminish the number of cases in which this method is not feasible and to minimize the effects of systemic therapies, attention was focused on identifying other therapeutic strategies which might provide a direct administration of the chemotherapeutic agent. Therefore, direct introduction of the cytostatic agent into the peritoneal cavity is expected to maximize the local effect of drug and to minimize the level of systemic adverse effects. Meanwhile, certain authors proposed the administration of pressurized agents in order to increase the rate of local absorption and the bioavailability (15-17).

\section{THE PRINCIPLES OF PRESSURIZED INTRAPERITONEAL AEROSOL CHEMOTHERAPY (PIPAC)}

PIPAC represents a laparoscopic controlled procedure of intraperitoneal administration of low dose cytostatic agent as an aerosol which combines multiple advantages: therefore local instillation of pressurized chemotherapeutic agents provides low systemic absorption, low systemic toxicity, homogenous intraperitoneal distribution and more appropriate tissue penetration when compared to standard intravenous chemotherapy (18-20).

The method has been initially investigated in the setting of unresectable peritoneal carcinomatosis from different origins, the type of the administered cytotoxic agent depending on the origin of the peritoneal le- sions. Due to the relatively low number of cases submitted to this therapeutic strategy, specific analysis according to the type of tumor and to the type of cytotoxic agent were initially impossible to be performed (21-24). Therefore at that moment it was very difficult to establish which cases could benefit most from this therapeutic strategy.

\section{THE EFFECT OF PIPAC ON UNRESECTABLE PERITONEAL CARCINOMATOSIS FROM COLORECTAL CANCER}

The first studies which aimed to investigate the role of PIPAC in treating unresectable peritoneal metastases from colorectal cancer were conducted by Teixeira and Demtröder on 20 patients and respectively 17 patients submitted to oxaliplatin based PIPAC for unresectable peritoneal metastases from colorectal cancer. In the first group the total number of performed procedures was of 37 while in the second group 48 procedures were performed. Both studies demonstrated into a retrospective manner that this procedure is associated with low morbidity rates due to a low systemic toxicity and to improved rates of cytoreductive surgery; however, the exact percent of cases in which the procedure was effective was difficult to be established as long as in certain cases the intraperitoneal route of administration was associated with intravenous systemic chemotherapy $(25,26)$. However other studies came to demonstrate that performing such therapies might induce a significant degree of local inflammation, making more difficult a future cytoreductive procedure (27).

An interesting study which has been recently published on this issue was conducted by Gockel et al. and included 13 patients with unresectable carcinomatosis from intestinal origin who were submitted to 26 PIPAC procedures between 2015 and 2018. The median peritoneal cancer index before the first procedure was 14 while the median volume of free intraperitoneal fluid was of $10 \mathrm{l}$; among the 13 cases there were six patients who received at least two procedures of PIPAC and reported significant decrease of the ascites volume, while the increase of the amount of ascites was reported in a single case. Meanwhile, peritoneal biopsies which were retrieved during each PIPAC procedure demonstrated the decrease of the number of tumoral cells in seven cases, a constant number of malignant cells in five cases while in three cases no respond was observed, increased number of malignant cells being reported after 2 PIPAC procedures. Meanwhile the authors demonstrated a strong correlation ship between the number of tumoral cells and the amount of free ascites. When it comes to the postoperative outcomes, no severe complications were reported; therefore, none of the cases developed systemic renal or hepatic 
toxicity; meanwhile transient modifications of the circulating levels of leukocytes and $C$ reactive protein have been reported. As for the long term outcomes, the authors reported an overall survival of 303 days (28).

\section{THEROLEOFREPETITIVEELECTROSTATIC PIPAC}

In order to maximize the effect of PIPAC, recent studies proposed a new technique for $\operatorname{PIPAC}(29,30)$. Electrostatic precipitation of the aerosols during PIPAC represents a novel therapeutic strategy which aims to increase the amounts of the cytotoxic agent at peritoneal level and to increase in the meantime tissue penetration of the drug (29). However, at the present moment data published so far underlined the fact that the procedure is associated with a significant deterioration of the quality of life especially within the first week after the administration of the cytotoxic agent, the systemic absorption of the drug being considerably higher than initially expected (30). Therefore the method is still under evaluation.

\section{CONCLUSIONS}

PIPAC represents a novel therapeutic strategy which has been tested in the last years in cases with unresectable peritoneal metastases from different primaries including colorectal cancer in order to offer a more efficient palliative effect and even to convert the lesions from unresectable to resectable and therefore to maximize the possibility of performing complete cytoreductive surgery. The method is associated with lower rates of systemic toxicity due to the low rates of systemic absorption; however, in the meantime it can induce local modifications such as severe intraperitoneal inflammation leading in this way to a more difficult surgical procedure whenever cytoreduction is tempted. However, larger, prospective studies are still needed in order to identify which cases could benefit most from this novel therapeutic strategy.

Conflict of interest: none declared Financial support: none declared

\section{REFERENCES}

1. van de Velde CJ, Boelens PG, Borras JM, Coebergh JW, Cervantes A, et al. EURECCA colorectal: multidisciplinary management: European consensus conference colon \& rectum. Eur J Cancer. 2014;50(1):e1-e34.

2. Weithorn D, Arientyl V, Solsky I, Umadat G, Levine R, Rapkin B, Leider J, In H. Diagnosis Setting and Colorectal Cancer Outcomes: The Impact of Cancer Diagnosis in the Emergency Department. Journal of Surgical Research. 2020;255:164-171.

3. Muller P, Woods L, Walters S. Temporal and geographic changes in stage at diagnosis in England during 2008-2013: A populationbased study of colorectal, lung and ovarian cancers. Cancer Epidemiol. 2020;67:101743.

4. Chow Z, Osterhaus P, Huang B, Chen Q, Schoenberg N, Dignan M, Evers M, Bhakta A. Factors Contributing to Delay in Specialist Care After Colorectal Cancer Diagnosis in Kentucky. J Surg Res. 2021;259:420-430.

5. Fidler I. The pathogenesis of cancer metastasis: the 'seed and soil' hypothesis revisited. Nat Rev Cancer. 2003;3:453-458.

6. Riihimäki M, Hemminki A, Sundquist J, Hemminki K. Patterns of metastasis in colon and rectal cancer. Sci Rep. 2016;6:29765.

7. Hugen N, van de Velde CJH, de Wilt JHW, Nagtegaal ID. Metastatic pattern in colorectal cancer is strongly influenced by histological subtype. Ann Oncol. 2014;25(3):651-657.

8. Holch JW, Demmer M, Lamersdorf C, Michl M, Schulz C, von Einem JC, Modest DP,
Heinemann V. Pattern and Dynamics of Distant Metastases in Metastatic Colorectal Cancer. Visc Med. 2017;33(1):70-75.

9. Lipsyc M, Yaeger R: Impact of somatic mutations on patterns of metastasis in colorectal cancer. J Gastrointest Oncol. 2015;6:645-649.

10. Missiaglia E, Jacobs B, D'Ario G, Di Narzo AF, Soneson C, Budinska E, Popovici V, et al. Distal and proximal colon cancers differ in terms of molecular, pathological, and clinical features. Ann Oncol. 2014;25:1995-2001.

11. Kamada Y, Hida K, Ishibashi H, Sako S, Mizumoto A, Ichinose M, Padmanabhan N, Yoshida S, Yonemura Y. Thirty-three long-term survivors after cytoreductive surgery in patients with peritoneal metastases from colorectal cancer: a retrospective descriptive study. World J Surg Oncol. 2021;19(1):31.

12. Hentzen JEKR, Rovers KP, Kuipers $H$, van der Plas WY, Been LB, et al. Impact of synchronous versus metachronous onset of colorectal peritoneal metastases on survival outcomes after cytoreductive surgery (CRS) with hyperthermic intraperitoneal chemotherapy (HIPEC): a multicenter, retrospective, observational study. Ann Surg Oncol. 2019;26:2210-2221.

13. Verwaal VJ, van Tinteren $H$, van Ruth $S$, Zoetmulder FA. Predicting the survival of patients with peritoneal carcinomatosis of colorectal origin treated by aggressive cytoreduction and hyperthermic intraperitoneal chemotherapy. Br J Surg. 2004;91:739-746.

14. Le QT, Fu KK, Kaplan M, Terris DJ, Fee WE, Goffinet DR. Treatment of maxillary sinus carcinoma: a comparison of the 1997 and 1977 American Joint Committee on cancer staging systems. Cancer. 1999;86:17001711.

15. Graversen M, Lundell L, Fristrup C, Pfeiffer $\mathrm{P}$, Mortensen BM. Pressurized IntraPeritoneal Aerosol Chemotherapy (PIPAC) as an outpatient procedure. Pleura Peritoneum. 2018;3:20180128.

16. Alyami M, Mercier F, Siebert M, Bonnot PE, Laplace N, Villeneuve L, Passot G, Glehen O, Bakrin N, Kepenekian V. Unresectable peritoneal metastasis treated by pressurized intraperitoneal aerosol chemotherapy (PIPAC) leading to cytoreductive surgery and hyperthermic intraperitoneal chemotherapy. Eur J Surg Oncol. 2021;47(1):128-133.

17. Graversen M, Fristrup C, Kristensen TK, Larsen TR, Pfeiffer P, Mortensen MB, Detlefsen S. Detection of free intraperitoneal tumour cells in peritoneal lavage fluid from patients with peritoneal metastasis before and after treatment with pressurised intraperitoneal aerosol chemotherapy (PIPAC). J Clin Pathol. 2019;72:368-3672.

18. Facy O, Al Samman S, Magnin G, Ghiringhelli F, Ladoire S, Chauffert B, Rat P, Ortega-Deballon P. High pressure enhances the effect of hyperthermia in intraperitoneal chemotherapy with oxaliplatin: an 
experimental study. Ann Surg.

2012;256:1084-1088.

19. Esquis $P$, Consolo D, Magnin G, Pointaire $P$, Moretto P, Ynsa MD, et al. High intraabdominal pressure enhances the penetration and antitumor effect of intraperitoneal cisplatin on experimental peritoneal carcinomatosis. Ann Surg. 2006;244:106-112.

20. Eveno C, Haidara A, Ali I, Pimpie C, Mirshahi M, Pocard M. Experimental pharmacokinetics evaluation of chemotherapy delivery by PIPAC for colon cancer: first evidence for efficacy. Pleura Peritoneum. 2017;2:103-109.

21. Robella M, Vaira M, De Simone M. Safety and feasibility of pressurized intraperitoneal aerosol chemotherapy (PIPAC) associated with systemic chemotherapy: an innovative approach to treat peritoneal carcinomatosis. World J Surg Oncol. 2016;14:128.

22. Nowacki M, Alyami M, Villeneuve L, et al. Multicenter comprehensive methodological and technical analysis of 832 pressurized intraperitoneal aerosol chemotherapy (PIPAC) interventions performed in 349 patients for peritoneal carcinomatosis treatment: an international survey study. Eur J Surg Oncol. 2018;44:991-6.
23. Willaert W, Sessink P, Ceelen W. Occupational safety of pressurized intraperitoneal aerosol chemotherapy (PIPAC). Pleura Peritoneum. 2017;2:121-8.

24. Blanco A, Giger-Pabst U, Solass W, Zieren J, Reymond MA. Renal and hepatic toxicities after pressurized intraperitoneal aerosol chemotherapy (PIPAC). Ann Surg Oncol. 2013:20:2311-2316.

25. Demtröder C, Solass W, Zieren J, Strumberg D, Giger-Pabst U, Reymond MA. Pressurized intraperitoneal aerosol chemotherapy with oxaliplatin in colorectal peritoneal metastasis. Colorectal Dis. 2016;18:364-371.

26. Teixeira Farinha H, Grass F, Labgaa I, Pache B, Demartines N, Hubner M. Inflammatory response and toxicity after pressurized intraperitoneal aerosol chemotherapy. J Cancer. 2018;9:13-20.

27. Siebert M, Alyami M, Mercier F, Gallice C, Villeneuve L, Berard F, Glehen O, Bakrin N, Kepenekian V. Severe hypersensitivity reactions to platinum compounds postpressurized intraperitoneal aerosol chemotherapy (PIPAC): first literature report. Cancer Chemother Pharmacol. 2019;83:425-430.
28. Gockel I, Jansen-Winkeln B, Haase L, Niebisch S, Moulla Y, Lyros O, Lordick F, Schierle K, Wittekind C, Thieme R. Pressurized IntraPeritoneal Aerosol Chemotherapy (PIPAC) in patients with peritoneal metastasized colorectal, appendiceal and small bowel cancer. Tumori. 2020;106(1):70-78.

29. Kakchekeeva T, Demtröder C, Herath NI, Griffiths D, Torkington J, Solaß W, Dutreix M, Reymond MA. In Vivo Feasibility of Electrostatic Precipitation as an Adjunct to Pressurized Intraperitoneal Aerosol Chemotherapy (ePIPAC). Ann Surg Oncol. 2016;23(5):592-598.

30. Lurvink R, Rovers K, Tajzai R, Wassenaar E, Moes FD, Pluimakers G, Wiezer M, Burger J, Nienhuijs S, Boerma D, Deenen M, de Hingh I. Quality of life and the systemic pharmacokinetics of oxaliplatin in patients with unresectable peritoneal metastases from colorectal cancer treated with repetitive electrostatic pressurized intraperitoneal aerosol chemotherapy (ePIPAC): The CRC-PIPAC trial. Ann Oncol. 2020;31(S3):211. 